\title{
Effect of the Extent of Resection on Survival Outcome in Glioblastoma: Propensity Score Approach
}

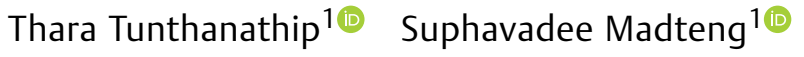 \\ 1 Division of Neurosurgery, Department of Surgery, Faculty of \\ Medicine, Prince of Songkla University, Hat Yai, Songkhla, Thailand \\ Arq Bras Neurocir 2021;40(1):37-43.

\begin{abstract}
Address for correspondence Thara Tunthanathip, M.D., Ph.D., Division of Neurosurgery, Department of Surgery, Faculty of Medicine, Prince of Songkla University, Hatyai, Songkhla, 90110, Thailand (e-mail: tsus4@hotmail.com).
\end{abstract}

\begin{abstract}
Objective To evaluate the effectiveness of the extent of resection (EOR) on survival outcome using propensity score-based approaches.

Materials and Methods A retrospective cohort study was performed in patients with newly diagnosed glioblastoma. Propensity score matching (PSM) and propensity score regression adjustment were used in the matched and unmatched dataset, respectively. Therefore, the Kaplan-Meier survival curve and Cox's regression analyses were performed to determine the effect of the EOR on survival outcomes.

Results One hundred and sixty-eight patients were included for analyzes. The total tumor resection in the unmatched dataset was $22.6 \%$ of all cases. Using PSM, incomplete tumor resection had an unfavorable survival outcome when compared with total tumor resection (hazard ratio (HR) 2.92, 95\% confidence interval [CI] 1.724.94). Additionally, biopsy and partial tumor resection were significantly associated with poor prognosis when compared with total tumor resection using propensity score regression adjustment (HR of biopsy $1.89,95 \% \mathrm{Cl} 1.13-3.16$ and $\mathrm{HR}$ of partial resection

Keywords

- glioblastoma

- extension of resection

- survival analysis

- propensity score

$1.89,95 \% \mathrm{Cl} 1.28-2.80)$.

Conclusions Patients with total tumor resection tend to have a more favorable prognosis than patients with partial tumor resection. The propensity score-based analysis is an alternative approach to evaluate the effect of an intervention that has limitations to perform a randomized controlled trial.
\end{abstract}

\section{Introduction}

Glioblastoma (GBM) is a malignant primary brain tumor that has a poor prognosis. Surgery is the first treatment option for histology-confirmed diagnosis and tumor burden reduction. ${ }^{1,2}$ From large retrospective cohort studies, extents of resection (EORs) ranging from 70 to $98 \%$ are the independent factor for significantly increased survival time. ${ }^{1,3-5}$ Moreover, Brown et al investigated in a systematic review and meta-analysis on the EOR on survival increment in patients with GBM and reported that total resection improves overall and progression-free survival. ${ }^{6}$ However, the lack of evidence from randomized clinical trials (RCTs) on the effect of the EOR related to survival advantages. This variable-EOR-has proven to be a limitation to the conduction of RCTs regarding ethical issues and other confounders. Owing to the infiltrative character of this type of tumor, not all GBMs are amenable to total tumor resection. ${ }^{7,8}$ From the literature review, multiple GBMs and tumor volume $\geq 30 \mathrm{ml}$ have been reported as limitations for complete tumor removal. In received

April 20, 2020

accepted

August 5, 2020

published online

October 16, 2020
DOI https://doi.org/ 10.1055/s-0040-1718424. ISSN 0103-5355.

\footnotetext{
(c) 2020. Sociedade Brasileira de Neurocirurgia. All rights reserved. This is an open access article published by Thieme under the terms of the Creative Commons Attribution-NonDerivative-NonCommercial-License, permitting copying and reproduction so long as the original work is given appropriate credit. Contents may not be used for commercial purposes, or adapted, remixed, transformed or built upon. (https://creativecommons.org/ licenses/by-nc-nd/4.0/) Thieme Revinter Publicações Ltda., Rua do Matoso 170, Rio de Janeiro, RJ, CEP 20270-135, Brazil
} 
addition, tumors involving eloquent areas have been reported to be a limitation for total resection because neurological impairments developed after tumor resection. ${ }^{9}$

Because confounding factors are critical problems that need to be addressed before analysis in observational studies attempting to estimate the effect of treatments, propensity score (PS) is one of the methods used for dealing with significantly confounding factors. ${ }^{10,11}$ From literature reviews, various techniques of the PS approach, such as matching, stratification, regression adjustment, and inverse probability of treatment weight, were effectively used in numerous studies to compare treated and controlled groups when there were limitations to perform RCT. Agrawal et al used PS-based analysis to evaluate the intracranial pressure monitoring on outcomes in severe traumatic brain injury, ${ }^{12}$ while Cepeda et al evaluated the effect of decompressive craniectomy in the postoperative expansion of traumatic intracerebral hemorrhage using PS methods. $^{13}$

Extent of resection is one of the variables that represents a limitation in conducting RCT. Alternatively, PS-based analysis is one of the methods that was used to evaluate the effect of EOR on survival outcomes. Therefore, the aims of the present study were to evaluate the effectiveness of EOR on survival outcomes using PS methods.

\section{Materials and Methods}

A retrospective cohort study was performed in the patients who had histologically-confirmed GBM and were newly treated between January 2000 and December 2018 in our institute. Additionally, a part of the study population was obtained from Tunthanathip et al, ${ }^{9,14}$ whose study mentioned factors associated with the EOR and genetic factors that could influence prognosis. The exclusion criteria were as follows: 1) unavailable medical record, 2) unavailable neuroimaging for tumor volume calculation, for both the preoperative and postoperative periods, and 3) unavailable update survival status.

In the present study, the EOR was defined according to Vecht et al and Bloch et al. ${ }^{15,16}$ Gross total resection was defined as less than $5 \%$ of residual tumor, as observed on postoperative neuroimaging. Partial resection was defined as resection of less than $95 \%$ of the tumor, as observed on postoperative neuroimaging. Biopsy was defined as an operation for tissue diagnosis only, without attempt of removing the tumor. Additionally, the percentage of resection was assessed by postoperative T1-weighted imaging with contrast.

The follow-up data were collected until June 2019 for survival outcome as update status (death or survival) or cause of death. The follow-up data were mainly collected when patients visited the outpatient clinics. Patients (or caregivers) who did not visit the hospital for appointments were interviewed by phone. Therefore, we also checked death records from the local municipality.

The present study was performed with the permission of the Ethical Committee of the Faculty of Medicine at Songklanagarind Hospital, Prince of Songkla University.

\section{Statistical Analysis}

The baseline characteristics included demographic variables, imaging, and therapeutic factors; these were obtained from studies of Tunthanathip et al that reported two variables, multiple GBMs, and tumor volume $\geq 30 \mathrm{ml}$, associated with the EOR. ${ }^{9,14}$ We excluded those patients with one or more missing data before estimating the propensity score (PS).

To control selection bias, we used PS methods. We used a logit model with a binary outcome (total resection and non-total resection) to estimate the PS. Therefore, the PSs were calculated and used as a covariate to control for confounding by indication or contraindication in the final model. In detail, two PS-based methods were performed: propensity score matching (PSM) and PS regression adjustment.

Both matched and unmatched datasets as well as baseline clinical characteristics were analyzed using descriptive analysis, presented as proportions and mean \pm standard deviation (SD).

In the PSM, we created a group of treated and controlled patients who were matched by the nearest neighbor matching algorithm with a ratio of $1: 1$. The effect of EOR on the survival of patients with GBM was analyzed by time-toevent. Survival curves were compared using the log-rank test. Cox regression analyses were performed, and the hazard ratio (HR) with 95\% confidence intervals (95\% CIs) was determined. In the study of Ahmadipour et al, the HR of biopsy compared with total resection was 2.33 (95\%CI 1.773.06) for death. ${ }^{17}$ Therefore, we calculated a sample size of 26 patients per group at $80 \%$ power and with an $\alpha$ level of 0.05 , using the Freedman method. ${ }^{18}$

Propensity score regression adjustment was used to run the outcome model of the association between EOR and survival controlled by PS and posttreatment variables from the unmatched dataset. All analyses were conducted using the $\mathrm{R}$ version 4.0.2 software ( $\mathrm{R}$ Foundation for Statistical Computing, Vienna, Austria) with the package MatchIt. ${ }^{19}$

\section{Results}

\section{Clinical Characteristics}

The 173 patients with GBM were obtained from the study by Tunthanathip et al. ${ }^{9,14}$, but 5 patients were excluded because of missing variables. Hence, 168 patients were included for analyses, and their baseline characteristics are shown in - Table 1, both unmatched and matched cohorts.

\section{Unmatched Cohort}

The unmatched cohort included 168 patients with GBM. The mean age was 51.4 years (SD 15.3), and half of the subjects were male. One-third of the GBMs commonly involved the temporal lobe, frontal lobe, and parietal lobe. Additionally, corpus callosum was found in $11.3 \%$ of the patients. The patients were divided by EOR as binary groups. Total tumor resection was observed in 38 patients $(22.6 \%)$ of the unmatched cohort, whereas the remaining (77.4\%) had either biopsy or partial tumor resection.

There were significant differences between total resection and non-total resection groups in several tumors and tumor 
Table 1 Baseline characteristic of patients divided by the extent of resection according to full cohort and propensity scorematched cohort

\begin{tabular}{|c|c|c|c|c|c|c|}
\hline \multirow[t]{2}{*}{ Factor } & \multicolumn{3}{|l|}{$\begin{array}{l}\text { Full cohort } \\
(N=168)\end{array}$} & \multicolumn{3}{|c|}{$\begin{array}{l}\text { Propensity score-matched cohort } \\
(N=76)\end{array}$} \\
\hline & $\begin{array}{l}\text { Total } \\
\text { resection } \\
\mathrm{n}(\%)\end{array}$ & $\begin{array}{l}\text { Non-total } \\
\text { resection } \\
n(\%)\end{array}$ & $P$-value & $\begin{array}{l}\text { Total } \\
\text { resection } \\
\mathrm{n}(\%)\end{array}$ & $\begin{array}{l}\text { Non-total } \\
\text { resection } \\
\mathrm{n}(\%)\end{array}$ & $P$-value \\
\hline Age, year & & & 0.11 & & & 0.15 \\
\hline$<50$ & $12(31.6)$ & $60(46.2)$ & & $12(31.6)$ & $18(47.4)$ & \\
\hline$\geq 50$ & $26(68.4)$ & $70(53.8)$ & & $26(68.4)$ & $20(52.6)$ & \\
\hline Gender & & & 0.70 & & & 0.81 \\
\hline Male & $20(52.6)$ & $73(56.2)$ & & $20(52.6)$ & $19(50.0)$ & \\
\hline Female & $18(47.4)$ & $57(43.8)$ & & $18(47.4)$ & $19(50.0)$ & \\
\hline Preoperative KPS & & & 0.11 & & & 0.10 \\
\hline$<80$ & $24(63.2)$ & $63(48.5)$ & & $24(63.2)$ & $17(44.7)$ & \\
\hline$\geq 80$ & $14(36.8)$ & $67(51.5)$ & & $14(36.8)$ & $21(55.3)$ & \\
\hline Frontal tumor & & & 0.33 & & & 0.81 \\
\hline No & $25(65.8)$ & $96(73.8)$ & & $25(65.8)$ & $24(63.2)$ & \\
\hline Yes & $13(34.2)$ & $34(26.2)$ & & $13(34.2)$ & $14(36.8)$ & \\
\hline Temporal tumor & & & 0.54 & & & 0.80 \\
\hline No & $26(68.4)$ & $82(63.1)$ & & $26(68.4)$ & $27(71.1)$ & \\
\hline Yes & $12(31.6)$ & $48(36.9)$ & & $12(31.6)$ & $11(28.9)$ & \\
\hline Thalamus/Basal ganglion & & & $0.58^{*}$ & & & $0.24^{*}$ \\
\hline No & $38(100)$ & $125(96.2)$ & & $38(100)$ & $35(92.1)$ & \\
\hline Yes & 0 & $5(3.8)$ & & 0 & $3(7.9)$ & \\
\hline Corpus callosum & & & $0.07^{*}$ & & & $0.35^{*}$ \\
\hline No & $37(97.4)$ & $112(86.2)$ & & $37(97.4)$ & $34(89.5)$ & \\
\hline Yes & $1(2.6)$ & $18(13.8)$ & & $1(2.6)$ & $4(10.5)$ & \\
\hline Eloquent area $^{\dagger}$ & & & 0.60 & & & 0.64 \\
\hline No & $17(44.7)$ & $52(40.0)$ & & $17(44.7)$ & $19(50.0)$ & \\
\hline Yes & $21(55.3)$ & $78(60.0)$ & & $21(55.3)$ & $19(50.0)$ & \\
\hline Initial leptomeningeal dissemination & & & $0.96^{*}$ & & & $1.00^{*}$ \\
\hline No & $34(89.5)$ & $116(89.2)$ & & $34(89.5)$ & $34(89.5)$ & \\
\hline Yes & $4(10.5)$ & $14(10.8)$ & & $4(10.5)$ & $4(10.5)$ & \\
\hline Number of tumors & & & $0.02^{*}$ & & & $1.00^{*}$ \\
\hline Single & $36(94.7)$ & $102(78.5)$ & & $36(94.7)$ & $36(94.7)$ & \\
\hline Multiple & $2(5.3)$ & $28(21.5)$ & & $2(5.3)$ & $2(5.3)$ & \\
\hline Tumor volume-ml & & & 0.003 & & & 1.00 \\
\hline$<30$ & $19(50.0)$ & $32(24.6)$ & & $19(50.0)$ & $19(50.0)$ & \\
\hline$\geq 30$ & $19(50.0)$ & $98(75.4)$ & & $19(50.0)$ & $19(50.0)$ & \\
\hline Postoperative KPS & & & 0.66 & & & 0.48 \\
\hline$<80$ & $24(63.2)$ & $77(59.2)$ & & $24(63.2)$ & $21(55.3)$ & \\
\hline$\geq 80$ & $14(36.8)$ & $53(40.8)$ & & $14(36.8)$ & $17(44.7)$ & \\
\hline Adjuvant therapy & & & 0.18 & & & 0.09 \\
\hline RT alone & $21(55.3)$ & 87 (66.9) & & $21(55.3)$ & $28(73.7)$ & \\
\hline RT with TMZ & $17(44.7)$ & $43(33.1)$ & & $17(44.7)$ & $10(26.3)$ & \\
\hline
\end{tabular}


Table 1 (Continued)

\begin{tabular}{|c|c|c|c|c|c|c|}
\hline \multirow[t]{2}{*}{ Factor } & \multicolumn{3}{|c|}{$\begin{array}{l}\text { Full cohort } \\
(N=168)\end{array}$} & \multicolumn{3}{|c|}{$\begin{array}{l}\text { Propensity score-matched cohort } \\
(N=76)\end{array}$} \\
\hline & $\begin{array}{l}\text { Total } \\
\text { resection } \\
\mathrm{n}(\%)\end{array}$ & $\begin{array}{l}\text { Non-total } \\
\text { resection } \\
\mathrm{n}(\%)\end{array}$ & $P$-value & $\begin{array}{l}\text { Total } \\
\text { resection } \\
\text { n (\%) }\end{array}$ & $\begin{array}{l}\text { Non-total } \\
\text { resection } \\
\mathrm{n}(\%)\end{array}$ & $P$-value \\
\hline IDH1 mutation & & & $0.83^{*}$ & & & $1.00^{*}$ \\
\hline Wild-type GBM & $36(94.7)$ & $122(93.8)$ & & $36(94.1)$ & $35(92.1)$ & \\
\hline Mutant GBM & $2(5.3)$ & $8(6.2)$ & & $2(5.3)$ & $3(7.9))$ & \\
\hline MGMT promoter methylation & & & $0.14^{*}$ & & & $0.24^{*}$ \\
\hline Methylated GBM & 0 & $7(5.4)$ & & 0 & $3(7.9)$ & \\
\hline Unmethylated GBM & $38(100)$ & $123(94.6)$ & & $38(100)$ & $35(92.1)$ & \\
\hline
\end{tabular}

Abbreviations: GBM, glioblastoma; IDH1, isocitrate dehydrogenase1; KPS, Karnofsky performance status; MGMT, O6-methylguanine-DNA methyltransferase; RT, radiotherapy; TMZ, temozolomide.

${ }^{*} p$-value of Fisher exact test.

${ }^{\dagger}$ Eloquent area defined tumor involved motor cortex, sensory cortex, visual center, speech center, basal ganglion, hypothalamus, thalamus, brainstem, dentate nucleus.

volume. In detail, multiple GBMs were frequently observed in the non-total resection group $(p=0.02)$, while tumor volume $<30 \mathrm{ml}$ was commonly found in the total resection group $(p=0.003)$.

\section{Matched Cohort}

Patients were equally divided into total resection and nontotal resection groups, according to PS. Therefore, 38 patients were assigned to each group. After matching, differences between the two groups regarding several tumors and tumor volume were noticeably absent.

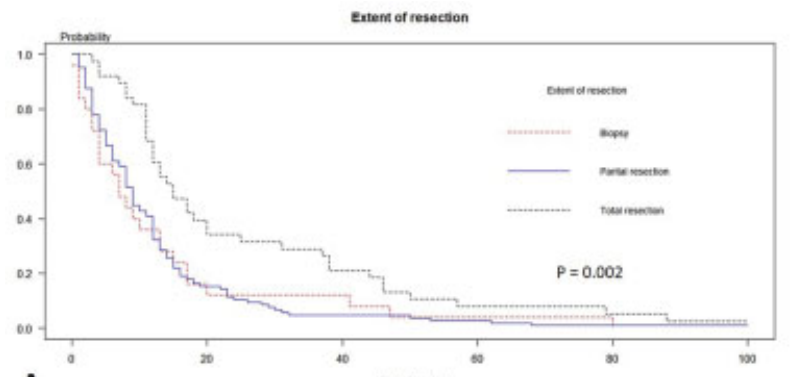

A

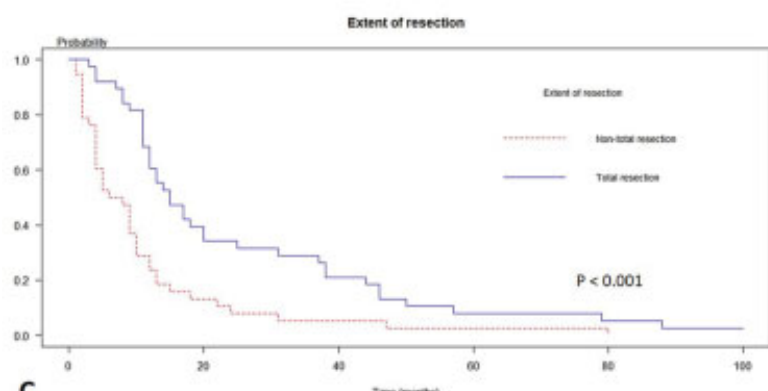

\section{Effect of EOR on Survival Outcome}

\section{PSM}

The Kaplan-Meier curves based on the EOR after PSM presented in - Fig. 1A-B show overall median survival time of 11.0 months (95\%CI 9.29-12.70). According to EOR subgroups, the median survival time of the total resection subgroup was 15 months (95\%CI 10.1-19.8), whereas the incomplete resection subgroup had median survival time of 6 months $(95 \% \mathrm{Cl}$ 2.6-9.3), as shown in - Table 2. There was a significant difference in prognosis between complete and incomplete
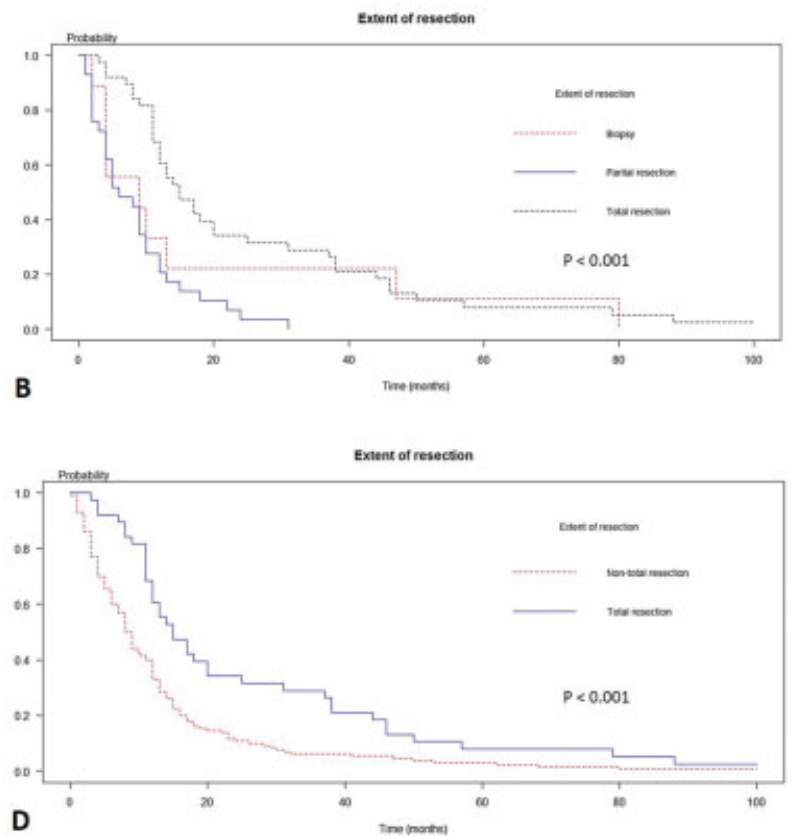

Fig. 1 The Kaplan-Meier curves of survival according to the extent of resection. (A) Bi-classifier of the extent of resection with matched data. (B) The extent of resection with matched data. (C) Bi-classifier of the extent of resection with unmatched data. (D) The extent of resection with unmatched data. 
Table 2 Median survival time and survival probability of the extent of resection subgroups

\begin{tabular}{|c|c|c|c|c|c|}
\hline \multirow[t]{2}{*}{ Dataset } & \multicolumn{2}{|c|}{$\begin{array}{l}\text { The binary outcome of the } \\
\text { extent of resection }\end{array}$} & \multicolumn{3}{|l|}{ Extent of resection } \\
\hline & $\begin{array}{l}\text { Total } \\
\text { resection } \\
(95 \% \mathrm{Cl})\end{array}$ & $\begin{array}{l}\text { Non-total } \\
\text { resection } \\
(95 \% \mathrm{Cl})\end{array}$ & $\begin{array}{l}\text { Total resection } \\
(95 \% \mathrm{CI})\end{array}$ & $\begin{array}{l}\text { Partial resection } \\
(95 \% \mathrm{Cl})\end{array}$ & $\begin{array}{l}\text { Biopsy } \\
(95 \% \mathrm{Cl})\end{array}$ \\
\hline \multicolumn{6}{|l|}{ Unmatched dataset } \\
\hline Median survival time-month & $\begin{array}{l}15.0 \\
(10.1-19.8)\end{array}$ & $\begin{array}{l}8.0 \\
(6.6-9.3)\end{array}$ & $\begin{array}{l}15.0 \\
(10.1-19.8)\end{array}$ & $\begin{array}{l}9.0 \\
(7.6-10.3)\end{array}$ & $\begin{array}{l}7.0 \\
(3.7-10.2)\end{array}$ \\
\hline 1-year probability of survival & $\begin{array}{l}60.5 \\
(46.8-78.2)\end{array}$ & $\begin{array}{l}33.0 \\
(25.9-42.2)\end{array}$ & $\begin{array}{l}60.5 \\
(46.8-78.2)\end{array}$ & $\begin{array}{l}32.3 \\
(24.5-42.6)\end{array}$ & $\begin{array}{l}36.0 \\
(21.3-60.7)\end{array}$ \\
\hline 2-year probability of survival & $\begin{array}{l}34.2 \\
(22.0-53.2)\end{array}$ & $\begin{array}{l}10.7 \\
(6.5-17.6)\end{array}$ & $34.2 \%(22.0-53.2)$ & $\begin{array}{l}10.4 \\
(5.9-18.3)\end{array}$ & $\begin{array}{l}12.0 \\
(4.1-34.7)\end{array}$ \\
\hline 3-year probability of survival & $\begin{array}{l}28.9 \\
(17.5-47.6)\end{array}$ & $\begin{array}{l}6.15 \\
(3.1-12.0) \\
\end{array}$ & $28.9 \%(17.5-47.6)$ & $\begin{array}{l}4.7 \\
(2.0-11.2)\end{array}$ & $\begin{array}{l}12.0 \\
(4.1-34.7) \\
\end{array}$ \\
\hline \multicolumn{6}{|l|}{ Matched dataset } \\
\hline Median survival time-month & $\begin{array}{l}15.0 \\
(10.1-19.8)\end{array}$ & $\begin{array}{l}6.0 \\
(2.6-9.3)\end{array}$ & $\begin{array}{l}15.0 \\
(10.1-19.8)\end{array}$ & $\begin{array}{l}6.0 \\
(1.7-10.2)\end{array}$ & $\begin{array}{l}9.0 \\
(0-23.6)\end{array}$ \\
\hline 1-year probability of survival & $\begin{array}{l}60.5 \% \\
(46.8-78.2)\end{array}$ & $\begin{array}{l}23.6 \% \\
(13.3-41.9)\end{array}$ & $60.5 \%(46.8-78.2)$ & $20.6 \%(10.1-42.2)$ & $33.3 \%(13.2-84.0)$ \\
\hline 2-year probability of survival & $\begin{array}{l}34.2 \% \\
(22.0-53.2)\end{array}$ & $\begin{array}{l}7.8 \% \\
(2.6-23.4)\end{array}$ & $34.2 \%(22.0-53.2)$ & $\begin{array}{l}3.4 \% \\
(0.5-2.3) \\
\end{array}$ & $\begin{array}{l}22.2 \% \\
(6.5-7.5) \\
\end{array}$ \\
\hline 3-year probability of survival & $\begin{array}{l}28.9 \% \\
(17.5-47.6)\end{array}$ & $\begin{array}{l}5.2 \% \\
(1.3-20.3)\end{array}$ & $28.9 \%(17.5-47.6)$ & - & $\begin{array}{l}22.2 \% \\
(6.5-7.5)\end{array}$ \\
\hline
\end{tabular}

Abbreviation: $95 \% \mathrm{Cl}, 95 \%$ confidence interval.

Table 3 Cox regression of the extent of resection on survival outcome according to propensity score methods

\begin{tabular}{|l|l|l|}
\hline Survival outcome & Hazard ratio (95\%Cl) & $p$-value \\
\hline Death & & \\
\hline Propensity score matching & Ref & \\
\hline Total resection & $1.42(0.68-2.98)$ & 0.34 \\
\hline Partial resection & $2.92(1.72-4.94)$ & $<0.001$ \\
\hline Biopsy & & \\
\hline Regression adjustment with the propensity score* & Ref & \\
\hline Total resection & $1.89(1.28-2.80)$ & 0.001 \\
\hline Partial resection & $1.89(1.13-3.16)$ & 0.01 \\
\hline Biopsy & & \\
\hline Progressive disease & & \\
\hline Propensity score matching & Ref & \\
\hline Total resection & $0.65(0.22-1.89)$ & \\
\hline Partial resection & $0.71(0.36-1.37)$ & 0.43 \\
\hline Biopsy & & 0.31 \\
\hline Regression adjustment with the propensity score & & \\
\hline Total resection & Ref & \\
\hline Partial resection & $1.01(0.62-1.65)$ & 0.07 \\
\hline Biopsy & $0.80(0.41-1.57)$ \\
\hline
\end{tabular}

${ }^{*}$ Covariates of the model comprised extent of resection (hazard ratio (HR) as shown in table), postoperative Karnofsky performance status (HR 1.044; $95 \% \mathrm{Cl} 0.76-1.43$ ), and propensity scores (HR 0.85; 95\% Cl 0.25-2.88).

${ }^{\dagger}$ Covariates of the model comprised extent of resection (hazard ratio (HR) as shown in table), postoperative Karnofsky performance status (HR 1.02; $95 \% \mathrm{Cl} 0.68-1.52$ ), and propensity scores (HR 2.06; 95\%Cl 0.44-9.56). 

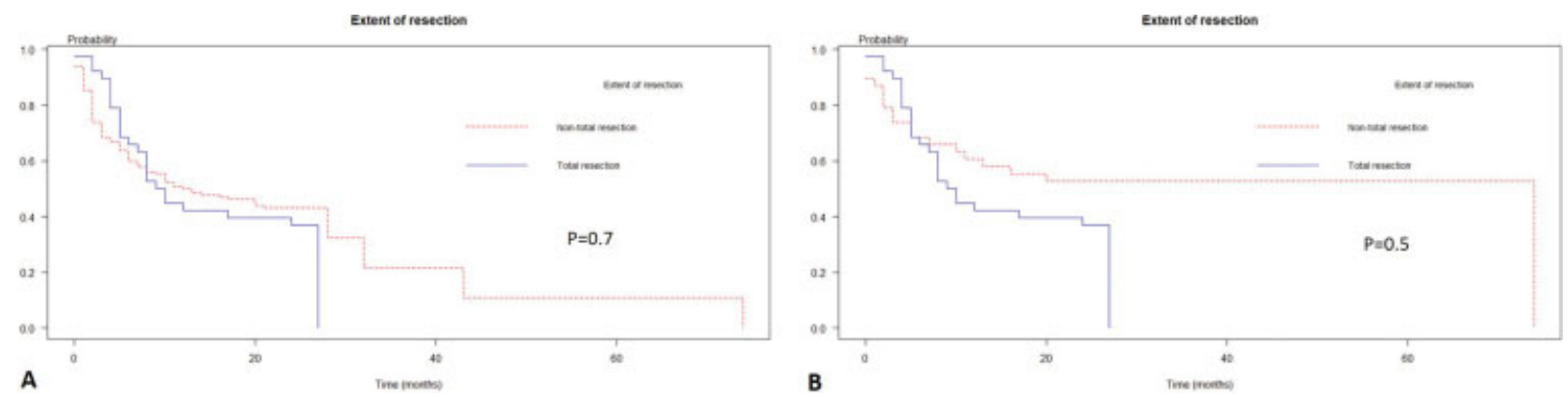

Fig. 2 The Kaplan-Meier curves of progression-free survival according to the extent of resection. (A) Matched data. (B) Unmatched data.

resection subgroups with a log-rank test $<0.001$. Using Cox proportional hazard regression analysis, a biopsy had shorter survival time than total tumor resection (HR 2.92, 95\%CI 1.724.94), and EOR is not associated with progression-free survival, as shown in - Table 3 and - Fig. 2A-B.

\section{PS Regression Adjustment}

The overall median survival time was 11.0 months (95\%CI 9.36-12.63) in the unmatched dataset. The 3-year survival probability of the total resection subgroup was $28.9 \%$, while incomplete resection subgroup had a 3-year survival probability in $5.2 \%$, as shown in - Table 2 . By PS regression adjustment, biopsy and partial tumor resection significantly associated with poor prognosis when compared with total tumor resection (HR of biopsy 1.89, 95\%CI 1.13-3.16 and HR of partial resection $1.89,95 \% \mathrm{CI} 1.28-2.80)$. Additionally, the EOR was not associated with progression-free survival, as summarized in -Table 3.

\section{Discussion}

Nowadays, lack of level I evidence exists for comparing the EOR and survival outcome in GBM. ${ }^{5}$ Although the effects of the EOR on survival outcomes have been reported in systematic review and meta-analysis, the achievement of an RCT examining EOR in patients with GBM remains unlikely. The PS is the alternative approach to control confounder before analyses of intervention. ${ }^{20}$ The patients were equally divided into intervention and control groups that were nearly RCT's assignment in PSM, whereas PSs was a covariate in the model in PS regression adjustment.

After adjustment with PS, total tumor resection significantly increased the survival advantages when compared with non-total resection in both PS methods. Lacroix et al. studied about the degree of resection in 416 patients with GBM and reported that $98 \%$ of tumor resection significantly increased survival time, ${ }^{1}$ while Stummer et al reported that total tumor resection was associated with longer survival for GBM patients, according to the re-stratifying study of the aminolevulinic acid (ALA) glioma study group. ${ }^{21,22}$

GBM is the infiltrative tumor that has an ill-defined border during tumor resection. Therefore, total resection is not easily performed in all cases. Fluorescence-guided resections with 5-aminolevulinic acid (5-ALA) significantly en- hanced rates of total resection compared with conventional microsurgical resection. However, the incremental cost with 5-ALA compared with traditional operation was $€ 9,021$ per QALY gained in economic evaluation. Therefore, fluorescence-guided resection is not the standard treatment, notably a limited-resource setting. ${ }^{24}$

Although the EOR was the independent prognostic factor in the present study, treatment biases to determine the degree of tumor removal have been reported, such as young age, tumor involving eloquent area, preoperative tumor volume, and several tumors. Tunthanathip et al reported that it was hard to achieve total removal in cases of multiple GBMs. Multicentric GBM is one of the subgroups of multiple GBMs in which the centers of the tumors are clearly disconnected from each other, such as in different lobes or bilateral tumors, with no apparent route of dissemination. ${ }^{25-27}$ Multi-stage operations need to be performed for total tumor resection in this subgroup.

To our knowledge, the present study is the first paper that demonstrated the effect of the EOR on survival outcomes by PS approaches. The limitations of the present study should be acknowledged. First, for the purpose of PSM, the patients were assigned into total resection and non-total resection groups, based on PS. Nine-two patients were removed from the dataset after matching that deleted patients cause decrease power of the study. ${ }^{28,29}$ However, the results after PSM still demonstrate the effect of total tumor resection, which was in. Alternatively, we tried to perform the PS regression adjustment method to preserve the total number of the study population for analyzing the effect of EOR. ${ }^{30}$ The concordance of results was observed from both PS approaches. For other limitations, fluorescence-guided resections with 5-ALA was not performed in the present study because it is unavailable in our institute.

\section{Conclusion}

Patients with total tumor resection had a statistical tendency of a more favorable prognosis than patients with non-total tumor resection. The PS-based analysis is a useful approach to evaluate the effect of the EOR on survival outcome that has limitations to conduct RCT.

\section{Authors' Contributions}

Conception and design: T. T. 
Administrative support: T. T., S. M.

Provision of study materials or patients: T. T., S. M.

Collection and assembly of data: T. T., S. M.

Data analysis and interpretation: T. T.

Manuscript writing: All authors

Final approval of manuscript: All authors

\section{Transparency Declaration}

Part of the study population was obtained from the studies by Tunthanathip et al. ${ }^{9,14}$ However, the present study focused on the effect of the EOR on prognosis.

\section{Conflict of Interests}

The authors have no conflict of interests to declare.

\section{References}

1 Lacroix M, Abi-Said D, Fourney DR, et al. A multivariate analysis of 416 patients with glioblastoma multiforme: prognosis, extent of resection, and survival. J Neurosurg 2001;95(02):190-198

2 Tunthanathip T, Ratanalert S, Sae-Heng S, Oearsakul T. Butterfly Tumor of the Corpus Callosum: Clinical Characteristics, Diagnosis, and Survival Analysis. J Neurosci Rural Pract 2017;8(Suppl 1): S57-S65

3 Trifiletti DM, Alonso C, Grover S, Fadul CE, Sheehan JP, Showalter TN. Prognostic Implications of Extent of Resection in Glioblastoma: Analysis from a Large Database. World Neurosurg 2017;103:330-340

4 Chaichana KL, Jusue-Torres I, Navarro-Ramirez R, et al. Establishing percent resection and residual volume thresholds affecting survival and recurrence for patients with newly diagnosed intracranial glioblastoma. Neuro-oncol 2014;16(01):113-122

5 Sanai N, Mirzadeh Z, Polley M-Y, et al. The value of glioblastoma extent of resection: a volumetric analysis of 500 patients. J Neurosurg 2010;113:A433

6 Brown TJ, Brennan MC, Li M, et al. Association of the Extent of Resection With Survival in Glioblastoma: A Systematic Review and Meta-analysis. JAMA Oncol 2016;2(11):1460-1469

7 Osorio JA, Aghi MK. Optimizing glioblastoma resection: intraoperative mapping and beyond. CNS Oncol 2014;3(05):359-366

8 Shinoda J, Sakai N, Murase S, Yano H, Matsuhisa T, Funakoshi T. Selection of eligible patients with supratentorial glioblastoma multiforme for gross total resection. J Neurooncol 2001;52(02): 161-171

9 Tunthanathip T, Madteng S. Factors associated with the extent of resection of glioblastoma. Precis Cancer Med 2020http://dx.doi. org $/ 10.21037 / \mathrm{pcm} .2020 .01 .01$

10 Newgard CD, Hedges JR, Arthur M, Mullins RJ. Advanced statistics: the propensity score-a method for estimating treatment effect in observational research. Acad Emerg Med 2004;11(09):953-961

11 Tanprasertkul C, Patumanond J, Manusook S, et al. Recurrence of Endometrioma Following Conservative Ovarian Endometrioma Cystectomy: Laparoscopy versus Laparotomy. J Med Assoc Thai 2015;98(98, Suppl 3):S96-S100

12 Agrawal D, Raghavendran K, Schaubel DE, Mishra MC, Rajajee V. A Propensity Score Analysis of the Impact of Invasive Intracranial Pressure Monitoring on Outcomes after Severe Traumatic Brain Injury. J Neurotrauma 2016;33(09):853-858. Doi: 10.1089/ neu.2015.4015

13 Cepeda S, Castaño-León AM, Munarriz PM, et al. Effect of decompressive craniectomy in the postoperative expansion of traumatic intracerebral hemorrhage: a propensity score-based analysis. J Neurosurg 2019;26:1-13. Doi: 10.3171/2019.2.JNS182025

14 Tunthanathip T, Sangkhathat S, Tanvejsilp P, Kanjanapradit K. Impact of IDH1 Mutation and MGMT Promoter Methylation in Patients with Glioblastoma. [dissertation]. Songkhla: Prince of Songkla University; 2020

15 Vecht CJ, Avezaat CJJ, van Putten WL, Eijkenboom WM, Stefanko SZ. The influence of the extent of surgery on the neurological function and survival in malignant glioma. A retrospective analysis in 243 patients. J Neurol Neurosurg Psychiatry 1990;53(06): 466-471

16 Bloch O, Han SJ, Cha S, et al. Impact of extent of resection for recurrent glioblastoma on overall survival: clinical article. J Neurosurg 2012;117(06):1032-1038

17 Ahmadipour Y, Kaur M, Pierscianek D, et al. Association of Surgical Resection, Disability, and Survival in Patients with Glioblastoma. J Neurol Surg A Cent Eur Neurosurg 2019;80 (04):262-268

18 Hsieh FY. Comparing sample size formulae for trials with unbalanced allocation using the logrank test. Stat Med 1992;11(08): 1091-1098. Doi: 10.1002/sim.4780110810

19 Ho D, Imai K, King G, et al. Package 'MatchIt'. https://cran.rproject.org/web/packages/MatchIt/MatchIt.pdf/2018 Accessed 13 March 2019.

20 Austin PC. An Introduction to Propensity Score Methods for Reducing the Effects of Confounding in Observational Studies. Multivariate Behav Res 2011;46(03):399-424

21 Stummer W, Pichlmeier U, Meinel T, Wiestler OD, Zanella F, Reulen HJALA-Glioma Study Group. Fluorescence-guided surgery with 5-aminolevulinic acid for resection of malignant glioma: a randomised controlled multicentre phase III trial. Lancet Oncol 2006;7(05):392-401

22 Stummer W, Reulen HJ, Meinel TALA-Glioma Study Group. , et al; . Extent of resection and survival in glioblastoma multiforme: identification of and adjustment for bias. Neurosurgery 2008; 62(03):564-576, discussion 564-576

23 Slof J, Díez Valle R, Galván J. Cost-effectiveness of 5-aminolevulinic acid-induced fluorescence in malignant glioma surgery. Neurologia 2015;30(03):163-168. Doi: 10.1016/j.nrl.2013.11.002

24 Tunthanathip T, Kanjanapradit K. Glioblastoma Multiforme Associated with Arteriovenous Malformation: A Case Report and Literature Review. Ann Indian Acad Neurol 2020;23(01):103-106

25 Liu Q, Liu Y, Li W, et al. Genetic, epigenetic, and molecular landscapes of multifocal and multicentric glioblastoma. Acta Neuropathol 2015;130(04):587-597

26 Thomas RP, Xu LW, Lober RM, Li G, Nagpal S. The incidence and significance of multiple lesions in glioblastoma. J Neurooncol 2013;112(01):91-97

27 Tunthanathip T, Sangkhathat S, Tanvejsilp P, Kanjanapradit K. The clinical characteristics and prognostic factors of multiple lesions in glioblastomas. Clin Neurol Neurosurg 2020;195:105891

28 Streiner DL, Norman GR. The pros and cons of propensity scores. Chest 2012;142(06):1380-1382

29 Tunthanathip T, Sangkhathat S. Temozolomide for patients with wild-type isocitrate dehydrogenase (IDH) 1 glioblastoma using propensity score matching. Clin Neurol Neurosurg 2020; 191:105712. Doi: 10.1016/j.clineuro.2020.105712

30 Cottone F, Anota A, Bonnetain F, Collins GS, Efficace F. Propensity score methods and regression adjustment for analysis of nonrandomized studies with health-related quality of life outcomes. Pharmacoepidemiol Drug Saf 2019;28(05):690-699. Doi: $10.1002 /$ pds.4756 